\title{
DESIGN DE INTERIORES: ENTRE O BACHARELADO E O TECNÓLOGO: UMA REFLEXÃO
}

\author{
João Carlos Vela \\ Universidade da Região de Joinville -UNIVILLE \\ Beatriz Andrielly de Souza Nascimento \\ Universidade da Região de Joinville -UNIVILLE \\ Franciane Feder \\ Universidade da Região de Joinville -UNIVILLE \\ Mikaella Istvandic \\ Universidade da Região de Joinville -UNIVILLE \\ Ana Claudia Jahn \\ Universidade da Região de Joinville -UNIVILLE
}

Resumo: O curso de design de interiores chegou no Brasil de modo gradativo, como uma evolução técnica da decoração, e foi se fortificando desde o início do século XX recebendo o título de "design de interiores" na década de 1980. Os cursos começaram a se propagar e a graduação de nível superior tomou dois rumos, os bacharelados e os tecnólogos. O crescimento dos cursos de design de interiores nos últimos anos é significativo, entretanto a modalidade do tecnólogo cresce na mesma proporção que o bacharelado declina, este parâmetro pode ser associado a fatores socioeconômicos e a focos educacionais diferenciados nas modalidades de formação. Além disso, a distribuição das ofertas dos cursos no território brasileiro é irregular, se concentrando nos centros industrializados e de turismo, que demandam um maior número de profissionais na área. Neste sentido o objetivo deste trabalho é procurar entender, por meio da análise das modalidades de formação dos cursos de Design de Interiores no Brasil, qual o viés de formação que melhor se aplica no país, uma vez que nos deparamos com questionamentos em relação a formação acadêmica dos profissionais, tais como a diferenciação entre cursos tecnólogos e bacharelados, já que os dois são focados no mercado de trabalho, mas possuem duração e abrangência de estudos diferenciados. Como metodologia realizou-se uma pesquisa junto ao site do Ministério da Educação e Cultura - MEC, onde estão disponíveis os dados sobre os cursos ativos e em extinção, necessários para a elaboração das análises, além de pesquisas em livros de design, artigos e sites que abordam o assunto desta pesquisa. Como resultado podemos apontar que o tecnólogo possui mais mercado no cenário brasileiro do que o bacharelado, entretanto fica o questionamento se este viés mais rápido de formação superior em Design de Interiores, é suficiente para capacitar os 
futuros profissionais, dado que esta profissão necessita de diferentes conteúdos, conteúdos estes que vão além da técnica pura e simples.

Palavras-chave: Design de Interiores, Tecnólogo, Bacharelado, Formação superior.

Abstract: The interior design course arrived in Brazil gradual way, as a technical evolution of decoration, and was fortifying since the early twentieth century given the title of "interior design" in the 1980s. The courses began to spread and upper-level undergraduate took two directions, the bachelors and technologists. The growth of interior design courses in recent years is significant, however mode technologist grows in proportion to the baccalaureate declines, this parameter can be associated with socioeconomic factors and the different educational focuses on the training arrangements. Furthermore, the distribution of offers courses in Brazil is uneven, concentrating in industrial centers and tourism, which require a greater number of professionals in the field. In this sense, the objective this work is to try to understand, through the analysis of training modalities of Interior Design courses in Brazil, which the bias of training that best applies in the country, since we are faced with questions regarding the formation academic professionals, such as differentiation between technologists and bachelor degrees, as both are focused on the labor market, but have duration and scope of different studies. The methodology carried out a survey to the website of the Ministry of Education and Culture - MEC, where available data on the assets and endangered courses, necessary for the preparation of analyzes, and research in design books, articles and websites addressing the subject of this research. As a result we can state that the technologist has more market in the Brazilian scenario than bachelor degree, but is the questioning whether this faster bias degree in Interior Design, is sufficient to enable future professionals, as this profession requires different content, content these that go beyond pure and simple technique.

Keywords: Interior design, Technologist, Bachelor, Higher Education

\section{INTRODUÇÃO}

A história do design de interiores é relativamente nova e pouco explorada, ocorrendo dúvidas de onde surgiu e se é vertente de alguma outra profissão. Sendo assim, há a necessidade de voltar até as raízes da arte e da arquitetura para buscar o viés ao qual pertence. Ao entender o contexto histórico da profissão é possível fazer um comparativo com o contexto atual e analisar sua evolução.

Neste sentido o objetivo deste trabalho é procurar entender, por meio da análise das modalidades de formação dos cursos de Design de Interiores no Brasil, qual o viés de formação que melhor se aplica no país, uma vez que nos deparamos com questionamentos em relação a formação acadêmica dos profissionais, tais como a 
diferenciação entre cursos tecnólogos e bacharelados, já que os dois são focados no mercado de trabalho, mas possuem duração e abrangência de estudos diferenciados.

Entender este panorama do Design de Interiores é importante para uma análise crítica do contexto atual, uma vez que este é reflexo de sua evolução e até então segue uma linha contínua de especificação técnica, bem como poderá ser possível enxergar linhas futuras que a profissão pode seguir referente a formas predominantes de cursos e os profissionais que estão sendo formados. Sendo assim, pretende-se fazer uma análise histórica e uma contextualização atual da formação acadêmica focando nos tecnólogos e bacharelados do Brasil, para que seja possível estabelecer uma diferenciação destes modos de formação, apontando o crescimento de cada um deles ao longo dos anos, levantar quantos destes cursos são oferecidos em instituições privadas e um possível caminho que o curso tende a seguir.

\section{HISTÓRIA DO DESIGN DE INTERIORES}

O Design de Interiores é um termo recente, mas em contrapartida a profissão vem sendo consolidada a muito mais tempo, uma vez que foi surgindo junto com as civilizações, com a necessidade de organização do espaço.

Segundo Jenny Gibbs (2015, pg. 14)

A profissão do designer de interiores é relativamente nova, pois, do ponto de vista histórico, as diferenças entre arquitetos, artesões e decoradores não eram bem definidas. Quando observamos a interação entre essas diferentes profissões através dos séculos, percebemos um interessante padrão de relações.

Não é possível falar de design sem falar dos movimentos artísticos, desde o antigo Egito, Grécia e Império Romano. Mas sem se ater a dados tão antigos, foi somente no século XVII que se pode afirmar que houve o primeiro decorador de interiores. Este período foi marcado pelo estilo barroco, e eram poucos os arquitetos que definiam os interiores das edificações que projetavam, uma vez que os projetos eram desenvolvidos por artesões especializados.

Segundo Jenny Gibbs (2015, pg. 14)

Durante o século XVII, os mecenas foram fundamentais para o
desenvolvimento do design de interiores e da arquitetura, especialmente na
França, onde Henrique IV concedeu proteção real aos artesões [...] Luís XIV
encomendou as extraordinárias intervenções no Palácio de Versalhes a
arquitetos como François Mansart, Louis Le Vau e Charles Le Brun. Os
aposentos projetados por Le Vau foram decorados por Le Brun, que os
transformou em algo extraordinário. Pode-se afirmar que Le Brun foi,
verdadeiramente, o primeiro decorador de interiores da história.

A evolução da decoração para o design de interiores foi ocorrendo ao longo dos grandes movimentos artísticos, sendo os mais notáveis: Art Nouveau, Cubismo, Futurismo, Dadaísmo, Surrealismo, Construtivismo, Art Decó, De Stijl e Bauhaus.

Com essa grande diversidade de estilos, a arquitetura e o design de interiores tiveram espaço para crescer, entretanto o marco principal na história do design foi a Revolução Industrial, que possibilitou a produção em massa de produtos que anteriormente eram feitos manualmente. Esse fato possibilitou uma democratização no ato de decorar, que antes era restrito a nobreza, a partir de meados do séc. XIX a 
decoração de interiores se torna mais tangível para as classes menos abastadas do primeiro mundo. Porém é apenas a partir do século XX que ela passa a existir em larga escala, tornando-se uma necessidade.

A primeira escola de design, Bauhaus, foi importantíssima para o desenvolvimento do design em geral, uma vez que mesmo após seu fechamento, seus discípulos continuaram a propagar os seus conhecimentos e estudos pelo mundo.

Ao longo do séc $X X$, iniciou-se um distanciamento entre a arquitetura e o design de interiores. Entretanto Jenny Gibbs (2015, pg.26) afirma que foi somente no século XXI que o design de interiores passou a ser realmente uma "profissão" reconhecida e deixou de ser um campo exclusivo de amadores talentosos e criativos. Atualmente o profissional requer conhecimento técnico aliado ao talento criativo e à habilidade de lidar com todos os aspectos de um projeto.

Segundo Paulo Oliveira (2008, web):

\begin{abstract}
Design de Interiores é uma evolução técnica e estética da Decoração. Com a necessidade urbana de espaços cada vez mais detalhados e personalizados aliado aos avanços tecnológicos em equipamentos, materiais e uso destes espaços, o profissional de decoração foi ficando para trás por não ter competência, conhecimentos e nem habilidade técnica para projetar
\end{abstract}

Contudo, ainda há dúvidas da diferença entre decoração, design de interiores e arquitetura, uma vez que o design é uma evolução técnica da decoração e cresceu aliada com a arquitetura. As diferenças principais hoje em dia destas profissões, segundo a CAU/PI (Conselho de Arquitetura e Urbanismo do Piauí), são as seguintes:

- Na Decoração não há conhecimentos técnicos, o que restringe sua função a escolher os componentes de decoração do ambiente sem alterar fisicamente a obra e nem projetar móveis.

- No Design de Interiores o profissional projeta um ambiente seguindo normas de ergonomia, acústica, térmico e luminotécnica, além de captar as reais necessidades dos clientes e concretiza-las através de projetos específicos. Porém seu trabalho restringe-se a ambientes internos podendo projeta-los por completo sem mexer na estrutura física.

- Na arquitetura o profissional é responsável por projetar um ambiente e acompanhar o seu desenvolvimento, podendo mexer na estrutura física dos imóveis. Seu trabalho se inicia a partir do momento em que se escolhe o terreno para a construção, ou seja, a implantação de seu projeto; com parecer sobre localização, legislações idílicas e urbanas, aspectos ambientais e topográficos. Entretanto, mesmo tendo uma formação abrangente o profissional não tem como foco do seu estudo o projeto de interiores.

\title{
2.1 Design de Interiores no Brasil
}

O design de Interiores no Brasil, assim como no resto do mundo, começou com a evolução técnica da decoração, e esta por sua vez começou a ser inserida no país na época da colonização.

Laerte Galesso (2015, web) aponta que a Decoração começou a prosperar no Brasil a partir da vinda da família real, no início do século XIX, pois a necessidade de manter o mesmo padrão de vida de Portugal fez com que a família real ordenassem a vinda do mobiliário, tapetes, acessórios, tecidos, etc. A evolução da Decoração no Brasil se deu principalmente no início do século XX, mas somente nas décadas de 1950 
à 1990, que foi ganhando forças e por fim foi oficializado, ganhando a denominação "Design de Interiores".

Em São Paulo, a primeira escola a ministrar cursos na área foi o Instituto de Arte e Design (IAD), fundada em 1959. Posteriormente, vieram a Escola Superior de Desenho Industrial (ESDI), oferecendo cursos de Graduação nas áreas de Design, os cursos Técnicos de Nível Médio, com a ETC Carlos de Campos e os cursos de Bacharelado em Belo Horizonte, Uberlândia e Rio de Janeiro. (GALESSO, 2015, web)

Entretanto é importante ressaltar que a formação destes primeiros cursos era restrita a design gráfico e de produto. Foi somente na década de 1980 que prosperaram os cursos livres de Decoração de Interiores. Na virada do século, surgiram cursos de diversos níveis em quase todos os Estados brasileiros.

Galesso (2015, web) cita também o fato que em 1980, é fundada a ABD, Associação Brasileira de Designers de Interiores, com o intuito de agregar a categoria, estabelecer normas para os exercícios da profissão e do mercado, definir o currículo básico para a formação do decorador e defender a categoria, entre outras atribuições importantes.

O termo "design de interiores" surgiu no Brasil na década de 1980, quando os cursos começaram a se propagar. Até essa época a área era conhecida como "Decoração", alguns chamavam de "Arquitetura de Interiores".

Em 1987, segundo Galesso (2015, web), surge a CASA COR, que é um importante evento de decoração no Brasil, o primeiro evento foi realizado em São Paulo, e é hoje reconhecida como a maior mostra de arquitetura e decoração das Américas e o segundo maior evento do mundo.

Laerte Galesso (2015, web) aponta que foi somente no final da década de 1990, que o Ministério da Educação e Cultura (MEC), na gestão de Paulo Renato de Souza, instituiu o curso de Nível Técnico em Design de Interiores. Para tanto, convidou a Associação Brasileira de Designers de Interiores (ABD), e as principais escolas de arte e design, que ofereciam cursos livres de Decoração de Interiores na época, para colaborarem na formatação dos Referenciais Curriculares Nacionais da Educação Profissional de Nível Técnico, que tem validade em todo o território nacional. Fica estabelecido assim, que deverá ser adotado pelo menos oitenta por cento do currículo aprovado, ficando cada instituição livre para completar os vinte por cento restante com as matérias a seu critério.

Esta instituição do curso de nível técnico de design de interiores, abriu as portas para a propagação dos cursos tecnólogos e bacharéis na área, uma vez que já existia nível superior em design gráfico e produto.

É importante ressaltar que no Brasil o Design de Interiores, assim como as demais habilitações do design, ainda não é uma profissão regulamentada.

\section{MODADELIDADES DE FORMAÇÃO NO BRASIL}

Com a evolução da decoração para o design de interiores, houve a necessidade de capacitação técnica e a busca por especializações, portanto observa-se dois vieses principais na graduação de interiores, que seriam os tecnólogos e bacharelados.

A demanda em relação as modalidades de formação no Brasil são bem distintas e atendem públicos com necessidades diferentes, mas ainda surge dúvidas em relação as diferenças entre cursos tecnólogos e bacharéis e qual graduação escolher. 


\subsection{Tecnólogo}

Quando se fala em um curso tecnólogo ainda é fácil associar a um profissional que cursou um técnico ou alguém que trabalhe na área da tecnologia, porém essa graduação é muito mais abrangente do que esta visão, podendo ser comparado ao Bacharel por uma série de elementos e características, como por exemplo, o desenvolvimento de desenhos arquitetônicos, fundamentos de design, projetos digitais, entre outros. O tecnólogo é muito recente, sendo suas características principais a curta duração, que é de aproximadamente 2 a 3 anos (1.600 a 2.400 horas) e o enfoque principal na parte prática da profissão. Pela curta duração o tecnólogo torna-se menos oneroso em comparação ao bacharel, sua formação é mais rápida e da mesma forma que qualquer outra modalidade de formação também recebe diploma de graduação superior. Portanto em muitas situações apresenta-se sendo mais viável, o que está provocando um forte crescimento desta modalidade de formação no país.

O curso é uma graduação de nível superior focado em uma área especifica de formação, pois visa uma forma muito mais direta e executa a capacitação do profissional para o mercado de trabalho abordando principalmente as disciplinas mais práticas e o lado técnico. O profissional está habilitado a criar projetos de interiores, considerando fatores técnicos, econômicos, legais e sustentáveis, podendo coordenar todo esse processo.

Assim como todos os cursos de graduação não é apenas focado para os estudantes que acabaram de sair do ensino médio, mas também para profissionais que não possuem diploma de graduação ou indivíduos que apenas querem se especializar em alguma área de modo rápido e com uma quantidade inferior de matérias a cumprir. As pessoas que cursam um tecnólogo podem normalmente dar continuidade a sua formação depois do curso, com uma especialização, uma extensão, um mestrado ou doutorado.

Com base nestas afirmações constata-se que o tecnólogo é muito procurado por ser um curso no qual os estudantes podem conseguir um diploma de graduação mais rapidamente, com uma mensalidade mais baixa, quando ofertado em um curso privado e comparado ao bacharelado na mesma situação, consequentemente se torna uma graduação mais acessível.

\subsection{Bacharelado}

A palavra graduação muitas vezes é usada erroneamente como sinônimo de bacharelado, entretanto graduação é um sistema de educação superior, que se refere ao primeiro título educacional adquirido por um indivíduo, podendo ser definido em três áreas: bacharelado, licenciatura e tecnólogos. O nível superior se tornou indispensável para o ingresso no mercado de trabalho, gerando uma preocupação em relação as graduações oferecidas e quais das três áreas melhor se encaixam em determinada profissão.

Inicialmente, o título de bacharel era fornecido a todos os indivíduos que concluíam o ensino médio, mas com o passar do tempo, passou a ser concedido somente com a conclusão de uma graduação de bacharelado. O curso de bacharelado tem em média a duração de 3 a 6 anos, e abrange as mais diversas áreas do conhecimento.

O bacharelado em design de interiores oferece um estudo que aborda diversas disciplinas, sendo assim o aluno tem a possibilidade de atuar em diferentes áreas 
relacionadas ao Design, uma vez que os aspectos da sua formação vão além da área projetual, isto pode ser verificado nas disciplinas de cunho mais generalistas tais como: Antropologia, Marketing, Estética, História da Arte, Introdução ao Design, Gestão de Design, entre outras. Estas possibilitam uma análise em relação aos indivíduos e aos trabalhos, de uma forma mais eclética, ampliando deste modo os aspectos ao projeto de interiores, onde o curso tecnólogo contém um foco mais voltado a pratica desenvolvida na profissão. Ao longo do bacharelado, o aluno se dedica a aprender e aprimorar seus conhecimentos projetuais e criativos, levando em consideração o impacto social de seu trabalho.

\section{PROCEDIMENTOS METODOLOGICOS}

Para o levantamento teórico da evolução do Design de Interiores e das modalidades de formação foi utilizado a pesquisa bibliográfica em livros e sites de interiores que proporcionaram a elaboração da fundamentação teórica do início do projeto. A plataforma do MEC foi utilizada para levantamento dos dados referentes a quantidades dos cursos oferecidos em 2016, sua distribuição em modalidades de formação, distribuição no território brasileiro, cursos em extinção e relação de cursos privados e públicos. Estes dados foram analisados para que fosse possível chegar ao perfil da formação profissional, de Design de Interiores, no Brasil.

\subsection{A SITUAÇÃO DAS GRADUAÇÕES DE DESIGN DE INTERIORES NO BRASIL}

Sabe-se que os cursos livres de design de interiores começaram a ser ofertados na década de 1980, mas foi somente na década de 1990 que os cursos de graduação começaram a se desenvolver e a se propagar no espaço brasileiro. Os dados referentes ao número de graduações oferecidos desde então não são claros, pelo fato de não se encontrar fontes que estabeleçam esta relação.

Entretanto, Laerte Galesso (2015, web) afirma que de acordo com levantamento coordenado pelo arquiteto Jéthero Cardoso, que é membro do Conselho Deliberativo da Associação Brasileira de Designers de Interiores (ABD), no ano de 2012 havia 182 cursos espalhados por todo o país, sendo 15 Bacharelados, 77 Tecnólogos e 90 Técnicos de Nível Médio, sem falarmos na grande quantidade de cursos complementares livres.

Com o objetivo de apresentar a evolução do curso, nas modalidades de tecnólogo e bacharelado, nos últimos 5 anos, realizou-se uma pesquisa no site do Mec, onde estão disponíveis os dados. Neste levantamento constatou-se que há 115 cursos de graduação, distribuídos em 106 tecnólogos e 9 bacharelados, sendo importante ressaltar que só foram contabilizados os cursos presenciais e ativos, desconsiderando os feitos a distância e os em extinção (que ainda estão ativos). Para demonstrar esta evolução ver figura 1. 


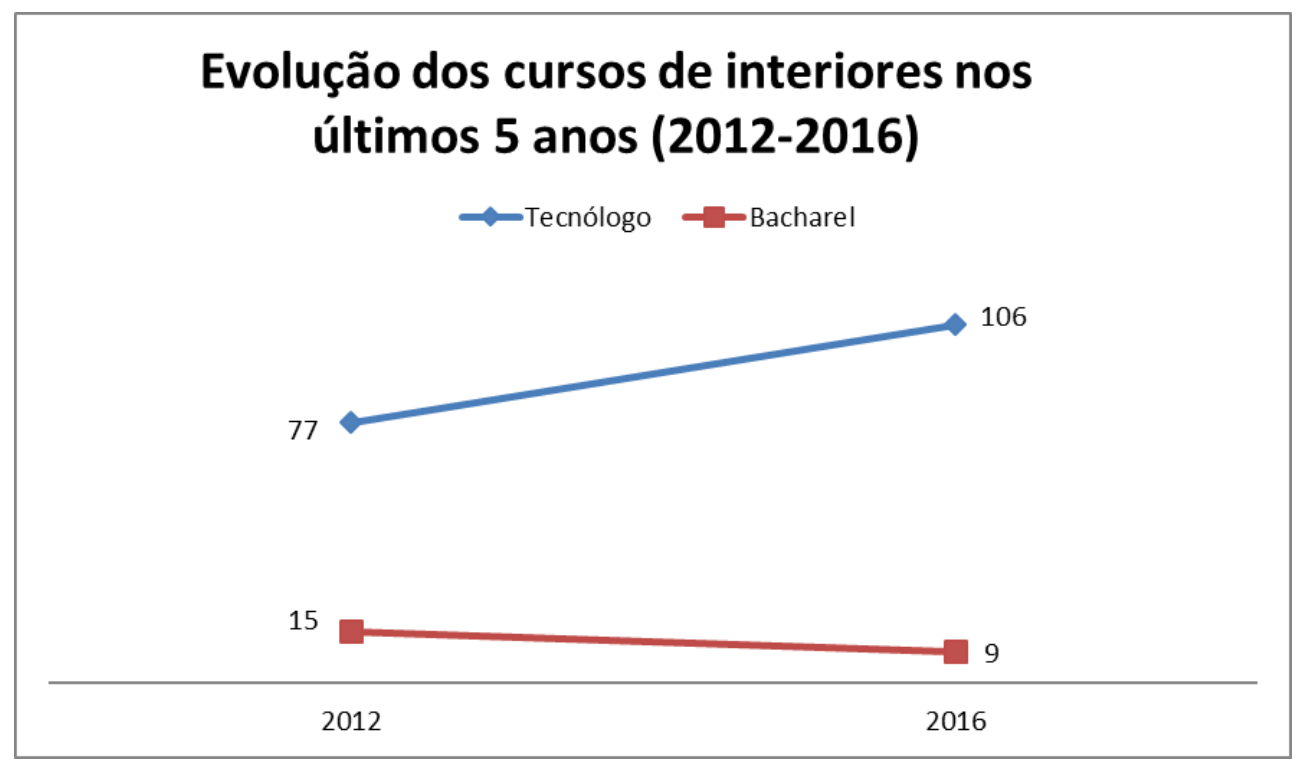

Figura 1 - Evolução dos cursos de interiores no Brasil nos últimos 5 anos (2012 - 2016).

Fonte: Elaborado pelos autores, com base na pesquisa realizada e dados do MEC.

É fácil perceber no gráfico que o que ocorre nos cursos tecnólogos é diretamente proporcional ao inverso do que ocorre nos cursos de bacharelados, no qual nos tecnólogos houve um crescimento de aproximadamente $38 \%$ e em contrapartida nos bacharelados há um declínio de 40\%. Em uma rápida observação fica a impressão que a medida que o bacharelado deixa de ser ofertado o tecnólogo supre a demanda do mercado. Porém não se pode desconsiderar que tanto em 2012 quanto em 2016 a proporção de ofertas de cursos nas duas modalidades sempre foi bastante expressiva a favor dos cursos tecnólogos, algo em torno de $85 \%$ em 2012 e 92\% em 2016, pode-se afirmar assim, que a oferta é quase unânime em favor dos cursos tecnólogos.

Com os dados totais dos cursos demonstrados no gráfico acima e considerando o ano de 2016, também se levou em consideração a distribuição geográfica dos cursos ativos de Design de Interiores no Brasil, na modalidade tecnólogo e bacharelado, no intuito de identificarmos como estes estão distribuídos pelo país, como mostra a figura 2.
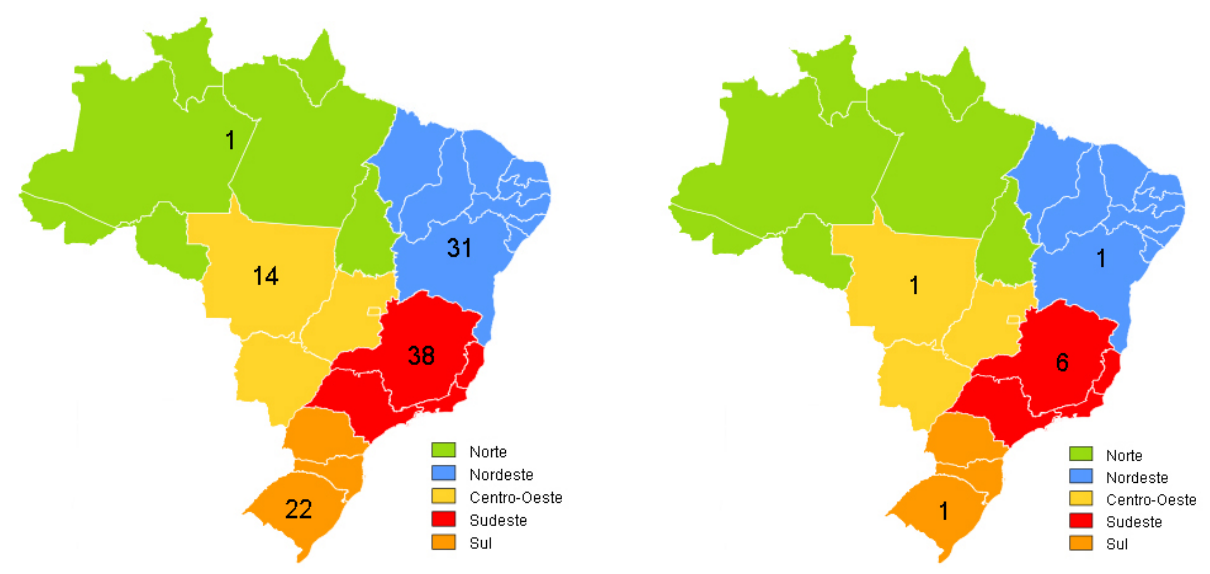

Figura 2 - Distribuição dos cursos Tecnólogos e Bacharelados de Design de Interiores no Brasil em 2016. Fonte: Elaborado pelos autores, com base em dados do e-MEC. 
As figuras mostram que nas duas modalidades de formação as ofertas dos cursos estão sendo feitas principalmente na região sudeste, respondendo por aproximadamente $40 \%$ de todos os cursos ofertados no país, sendo no bacharelado a diferença com as demais regiões muito mais significativas, algo em torno de $66 \%$ dos cursos. Já nos tecnólogos há bastantes ofertas de cursos também na região nordeste e sul do país.

Com este parâmetro levanta-se o questionamento do porque desta má distribuição dos cursos, esta situação pode ser associada à fatores como industrialização, população e turismo nas regiões com maior número de ofertas, uma vez que isto aumenta a demanda por designers de interiores.

As análises feitas até o momento desconsideram os cursos em extinção no país, mesmo que estes ainda estejam ativos, entretanto buscou-se os dados referentes de quantos cursos de graduação estão na situação de extinção no país, conforme a figura 3.

\section{Cursos Design de Interiores em Extinção no Brasil}

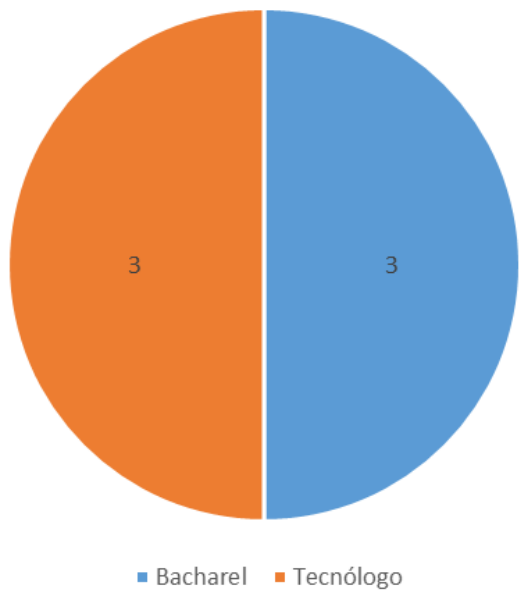

Figura 3 - Cursos de Design de Interiores em extinção no Brasil.

Fonte: Elaborado pelos autores, com base em dados do e-Mec.

Observa-se então que são 6 cursos de graduação de design de interiores no país em extinção, destes $50 \%$ são tecnólogos e $50 \%$ bacharelados. Entretanto é importante ressaltar que não necessariamente estes cursos serão extintos, mas que podem somente estarem passando por alguma alteração, como é o caso da Universidade da Região de Joinville- UNIVILLE, que está passando por uma alteração na nomenclatura, que ao invés de Design de Interiores está sendo modificado para Design, mas com linha de formação em Interiores.

Com este parâmetro e a afirmação dos cursos tecnólogos possuírem um valor mais acessível que o bacharelado surge a questão de quantos dos cursos ofertados no país são privados e quantos são públicos, diante disto levantou-se estes dados, que podem ser observados na figura 4. 
Cursos Tecnólogos no Brasil

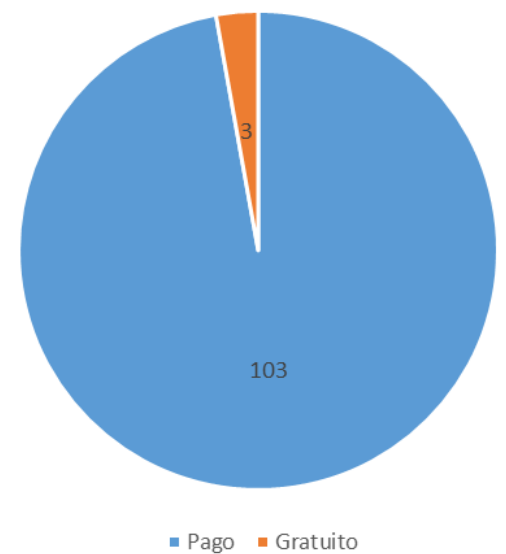

Cursos Bacharelados no Brasil

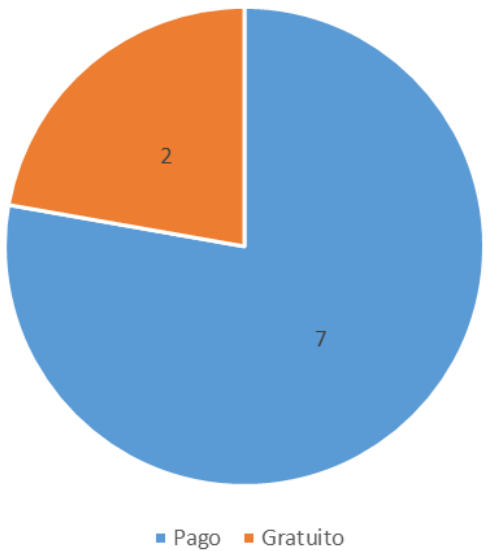

Figura 4: Distribuição dos cursos, tecnólogos e bacharelados, pagos e gratuitos no Brasil Fonte: Elaborados pelos autores, com base nos dados do e-Mec

Com base na imagem é possível observar que aproximadamente $97 \%$ dos cursos tecnólogos são pagos, ou seja, quase a totalidade dos cursos são ofertados por instituições privadas, já no bacharelado aproximadamente $78 \%$ também estão na mesma situação.

As análises feitas até então dos cursos tecnólogos e bacharelados no Brasil, tiveram o objetivo de mostrar a situação das duas modalidades de formação no cenário atual, apontando seu desenvolvimento, ofertas e distribuições.

Deste modo e em função dos dados coletados, pode-se perceber qual o perfil dos cursos de Design de Interiores ofertados no Brasil. Possui-se hoje um curso de perfil tecnólogo e privado, situado basicamente nas regiões sul e sudeste, entretanto a questão que fica é se este viés mais rápido de formação superior em Design de Interiores, é suficiente para capacitar os futuros profissionais, dado que esta profissão necessita de diferentes conteúdos, conteúdos estes que vão além da técnica pura e simples.

\section{CONSIDERAÇÕES FINAIS}

Com a demanda por especificações técnicas na arte da decoração, surgiu o design de interiores e com isto a necessidade de graduações de níveis superiores, nesta pesquisa analisou-se o contexto histórico da profissão para que fosse possível montar e estudar o panorama atual das modalidades de formação do curso. Apontouse as características principais dos tecnólogos e bacharelados, no qual constatou-se que enquanto o tecnólogo é focado na parte prática dos projetos e possui uma formação curta, o bacharelado é muito mais amplo possibilitando a elaboração de projetos centrados na individualidade de cada cliente ao invés de projetos técnicos padrões e sua formação é mais longa.

O objetivo deste estudo foi procurar entender, por meio da análise das modalidades de formação dos cursos de Design de Interiores no Brasil, qual o viés de formação que melhor se aplica no país, considerando a evolução do tecnólogo e bacharelado, a linha de estudo que cada uma aborda na sua formação e a demanda do mercado atual para as duas modalidades de formação. 
A diferenciação de carga horaria das modalidades de formação, se reflete na abrangência das disciplinas e no custo necessário para concluir a formação superior, isto ressaltamos, somente se aplica quando comparamos instituições de mesma natureza jurídica. Por esta analise observamos que o bacharelado se torna mais oneroso que o tecnólogo e em função disto, esta realidade propicia ou impulsiona uma oferta maciça de cursos tecnólogos oferecidos por instituições privadas, o que leva ao entendimento, que essa grande disponibilidade de cursos tecnólogos além das suas características acadêmicas e pedagógicas, também possui uma forte tendência mercadológica.

Os tecnólogos por serem então mais acessível acabam se tornando quase que a única opção de graduação uma vez, que a oferta de cursos públicos e portanto gratuitos, praticamente não existem no país, como demonstrado no figura 4 acima. Esta situação, e não se pode ignorar a difícil fase econômica e política pelo que o Brasil hoje se encontra, também favorece o crescimento da oferta de curso de nível superior na modalidade tecnólogo.

Considerando que a demanda por designers de interiores se concentram em regiões industrializadas e de turismo, imagina-se que os profissionais necessitam de conhecimentos abrangentes em áreas que vão além do técnico, como por exemplo movimentos artísticos do passado que podem ser retomados na atualidade ou a ergonomia adequada no ambiente, entretanto os cursos com maior oferta no cenário brasileiro, que é o tecnólogo, não abrangem ou não tem como prioridade estes conhecimentos diversos.

A questão que fica, e que seria importante novos estudos nesse sentido, é a de verificar se este viés mais rápido de formação superior em Design de Interiores, é suficiente para capacitar os futuros profissionais, dado que esta profissão necessita de diferentes conteúdos, conteúdos estes que vão além da técnica pura e simples.

\section{REFERÊNCIAS}

Centro Tecnológico Positivo. Design de Interiores. Disponível na internet por http em: <http://www.ctpositivo.edu.br/cursos-de-tecnologia/design-de-interiores $>$. Acesso em 25 maio 2016

Faculdade Estácio. Design de Interiores. Disponível na internet por http em: $<$ http://portal.estacio.br/graduacao/design-deinteriores.aspx?query_curso=design\%20de\%20interiores>. Acesso em 29 maio 2016

FSG. Curso de graduação - Conceito e definição. Disponível na internet por http em: <http://fsg.br/blog/curso-de-graduacao-conceito-e-definicao >. Acesso em 28 maio 2016

GALESSO, Laerte. Breve História da Decoração. Disponível na internet por http em: <http://www.abra.com.br/artigos/59-breve-historia-da-decoracao>. Acesso em 29 maio 2016

GIBBS, Jenny. Design de Interiores: Guia útil para estudantes e profissionais. 1. Ed. São Paulo: editora G. Gili, 2015. 
Guia do Estudante. Design de Interiores. Disponível na internet por http em: $<$ http://guiadoestudante.abril.com.br/profissoes/artes-design/design-interiores684670.shtml>. Acesso em 26 maio 2016

KLÖPSCH, Cássia; DA COSTA, Filipe Campelo Xavier. Gestão do Design Usando o design para construir valor de marca e inovação corporativa. Porto Alegre, 2011.

Ministério da Educação e Cultura. Instituições de Educação Superior e Cursos Cadastrados. Disponível na internet por http em: <http://www.emec.mec.gov.br/>. Acesso em 29 maio 2016

MORGENSTERN, Elenir; AGUIAR, Victor. Cenários culturais e sociais do Design. Joinville, 2015.

OLIVEIRA, Paulo LD. Tudo o que você precisa saber sobre Design de Interiores e Ambientes. Disponível na internet por http em: $<$ https://paulooliveira.wordpress.com/2008/06/30/tudo-que-voce-precisa-sabersobre-design-de-interiores-e-ambientes/>. Acesso em 25 maio 2016

Pontifícia Universidade Católica do Paraná. Sobre o Tecnólogo. Disponível na internet por http em: <http://www.pucpr.br/tecnologos/>. Acesso em 26 maio 2016

PORTO, Gabriella. Diferenças entre tecnólogo, bacharelado e licenciatura. Disponível na internet por http em: <http://www.infoescola.com/educacao/diferencas-entretecnologo-bacharelado-e-licenciatura/>. Acesso em 29 maio 2016

RIZZO, Garibaldi. A diferença entre $\mathrm{o}$ arquiteto, $\mathrm{o}$ design de interiores e o decorador. Disponível na internet por http em: <http://novo.caupi.org.br/?p=3217>. Acesso em 25 maio 2016

SILVA, Alberto Vicente. Curso de Tecnólogo é considerado de nível superior? Disponível na internet por http em:

<http://www.concursosnobrasil.com.br/blogs/guia-do-concurseiro/curso-detecnologo-e-considerado-de-nivel-superior.html>. Acesso em 28 maio 2016

Universidade da Amazônia. Tecnologia em Design de Interiores. Disponível na internet por http em:

<http://www.unama.br/novoportal/ensino/curtaduracao/cursos/tecdesigninteriores/i ndex.php?option=com_content $\&$ view=article\&id=108\&ltemid=231>. Acesso em 24 maio 2016

Universidade Anhembi Morumbi. Tecnologia em Design de Interiores. Disponível na internet por http em: <http://portal.anhembi.br/cursos/tecnologia-em-design-deinteriores/\#tab1>. Acesso em 26 maio 2016

Universidade da Região de Joinville. Design de Interiores. Disponível na internet por http em: <http://www.univille.edu.br/pt-BR/departamentos/designinteriores/index/598246>. Acesso em 25 maio 2016

SCOZ, Monique Vandresen Murilo; Ramalho, Sandra. Desafios do Design.

Florianópolis, 2014.

VELA, João Carlos. Design de Produto: as concepções de formação pela perspectiva de seus docentes. São Paulo, 2010. 